\title{
WATER CHAMBER GEOMETRY AND STABILIZER CONSTRUCTION EFFECT ON WATER PRESSURE DISTRIBUTION OF HIGH PRESSURE DESCALING NOZZLES
}

\begin{abstract}
Michal POHANKA, Jiří KVAPIL, Jozef HRABOVSKÝ•
Abstract: High pressure descaling nozzles are used mainly for removing oxides from hot steel products. The homogeneity and intensity of water pressure distribution on the oxidised surface are very important characteristics for a description of nozzle characteristics. The higher the water impact is the more scales are removed and the surface is cleaner. The results of water impact depend not only on the used nozzle but also on the used water stabilizer and geometry of water chamber in which the nozzle with the stabilizer is mounted. To analyse the real water pressure distribution a special measuring device was used that enables us to scan pressure distribution of the spraying nozzle. Two different nozzles were used, each with a different construction of a stabilizer. The nozzles with the stabilizers were mounted in the water chambers with different geometries. It was confirmed that water chamber geometry has a slight effect on water pressure distribution. It was also found that for some geometry of the stabilizer the water chamber geometry has a bigger effect and for some smaller. The measured values are also compared with numerical simulations in the water chamber and the stabilizer.
\end{abstract}

\section{INTRODUCTION}

The requirements of the steel industry, twinned with the customers' need for steel products with high quality surface layers without residuals and rolled oxides has led to improvement in finding the most effective way of fulfilling these needs. The most widely used method for removing oxides is high pressure hydraulic descaling [1]. High pressure hydraulic descaling is mainly used for removing secondary scales at high temperatures during the rolling mill process. To improve and to achieve optimal settings for this method we need to examine all the parameters that can be used for this optimization. The influence of the individual parameters on high pressure hydraulic descaling can be studied by experiments or numerical simulation. The basic parameters of high pressure hydraulic descaling that have an impact on the final surface quality are the spray length, spray width, nozzle distance, nozzle spray angel and so on [2]. All these parameters can be summarized into one variable impact pressure, which characterizes this process [3], [4]. Streamline hydraulic descaling can be achieved by a suitable design of the inlet piping, felicitous water stabilizer or proper nozzle. This article is focused on the study of

\footnotetext{
- Ing. Michal Pohanka Ph.D., pohanka@fme.vutbr.cz, Ing. Jiří Kvapil, kvapil@LPTaP.fme.vutbr.cz Ing. Jozef Hrabovský, hrabovsky@LPTaP.fme.vutbr.cz

Brno University of Technology, Faculty of Mechanical Engineering, Heat Transfer and Fluid Flow Laboratory, Technicka 2896/2, 61669 Brno, Czech Republic
}

This is an Open Access article distributed under the terms of the Creative Commons Attribution License 2.0, which permits unrestricted use, distribution, and reproduction in any medium, provided the original work is properly cited. 
three types of inlet piping design and two types of water stabilizer. Research studying the impact of the individual components on the impact pressure distribution was performed by experimental measurements and supported by numerical simulations. A combination of these two methods leads to effective research and solving problems.

\section{EXPERIMENTS}

To investigate the influence of various input water streams on the system consisting of the nozzle with stabilizer two high pressure descaling nozzles were chosen (A and $B$ nozzle). Nozzle A has a higher flow rate and nozzle $B$ has a smaller flow rate. The bigger nozzle A was used with a water pressure of $25 \mathrm{MPa}$. The corresponding measured water flow rate was $2.3 \mathrm{l} / \mathrm{s}$. The small nozzle $B$ has a water flow rate of $1.2 \mathrm{l} / \mathrm{s}$ for used water pressure $10 \mathrm{MPa}$. Both nozzles $\mathrm{A}$ and $\mathrm{B}$ have similar spray angles $28^{\circ}$ and $30^{\circ}$, respectively.

The big difference is the geometry of the used water stream stabilizer for each nozzle. Nozzle A was used with the older style of stabilizer C. Nozzle B was used with a newly designed stabilizer $D$. There are two main differences between both stabilizers, $C$ and $D$. Stabilizer $C$ is flat on top while stabilizer $D$ has a half sphere on top (see Figure 1 ). Stabilizer $C$ is filled with a stick in the centre and the ribs connect the outer wall with the inner stick. Stabilizer $D$ is empty in the centre and the ribs are connected only to the outside wall.
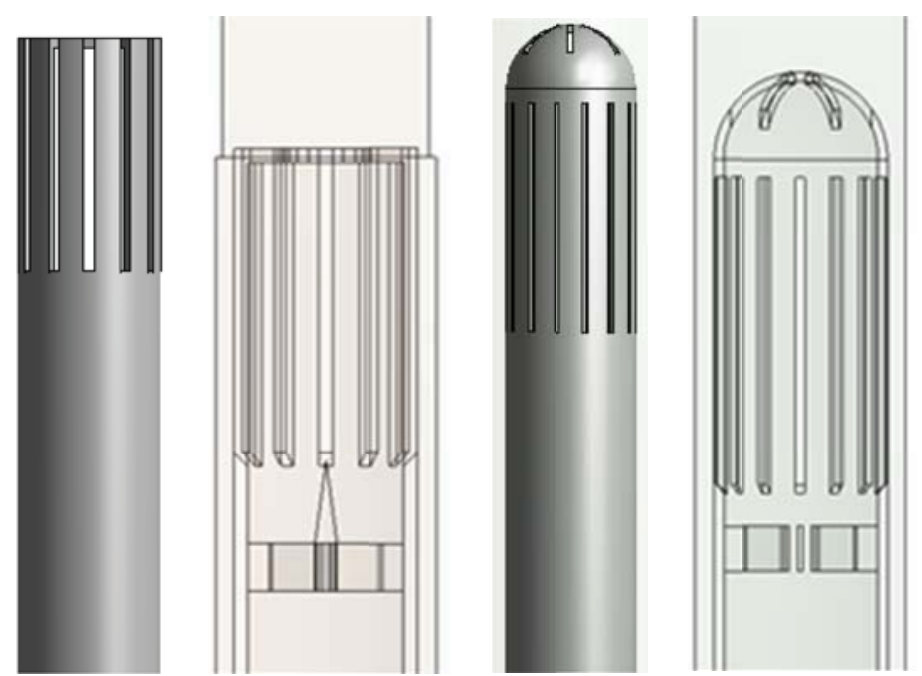

Figure 1: Water stabilizer C and D

To investigate the nozzles with the stabilizers a straight pipe and a bent pipe were used for water feeding (see Figure 2). Nozzle A with stabilizer $C$ was also tested in a bigger chamber with a side inlet. The nozzle with the stabilizer was also turned by an offset angle of $180^{\circ}$ to see a side inlet effect to the stabilizer. Experiment E6 is equal to E7 to see the repeatability of the measurements. See Table 1 for a more detailed list of the measurements. 
Table 1: List of experiments

\begin{tabular}{|cccccccc|}
\hline Exp. & Nozzle & Stabilizer & $\begin{array}{c}\text { Spray angle } \\
{\left[{ }^{\circ}\right]}\end{array}$ & $\begin{array}{c}\text { Pressure } \\
{[\mathrm{MPa}]}\end{array}$ & $\begin{array}{c}\text { Spray height } \\
{[\mathrm{mm}]}\end{array}$ & $\begin{array}{c}\text { Offset angle } \\
{\left[{ }^{\circ}\right]}\end{array}$ & Mounting \\
\hline E1 & A & C & 28 & 25 & 100 & 0 & chamber \\
E2 & A & C & 28 & 25 & 100 & 180 & chamber \\
E3 & A & C & 28 & 25 & 100 & 180 & pipe $0^{\circ}$ \\
E4 & A & C & 28 & 25 & 100 & 180 & pipe $90^{\circ}$ \\
\hline E5 & B & D & 30 & 10 & 100 & 0 & pipe $0^{\circ}$ \\
E6 & B & D & 30 & 10 & 100 & 0 & pipe $90^{\circ}$ \\
E7 & B & D & 30 & 10 & 100 & 0 & pipe $90^{\circ}$ \\
\hline
\end{tabular}

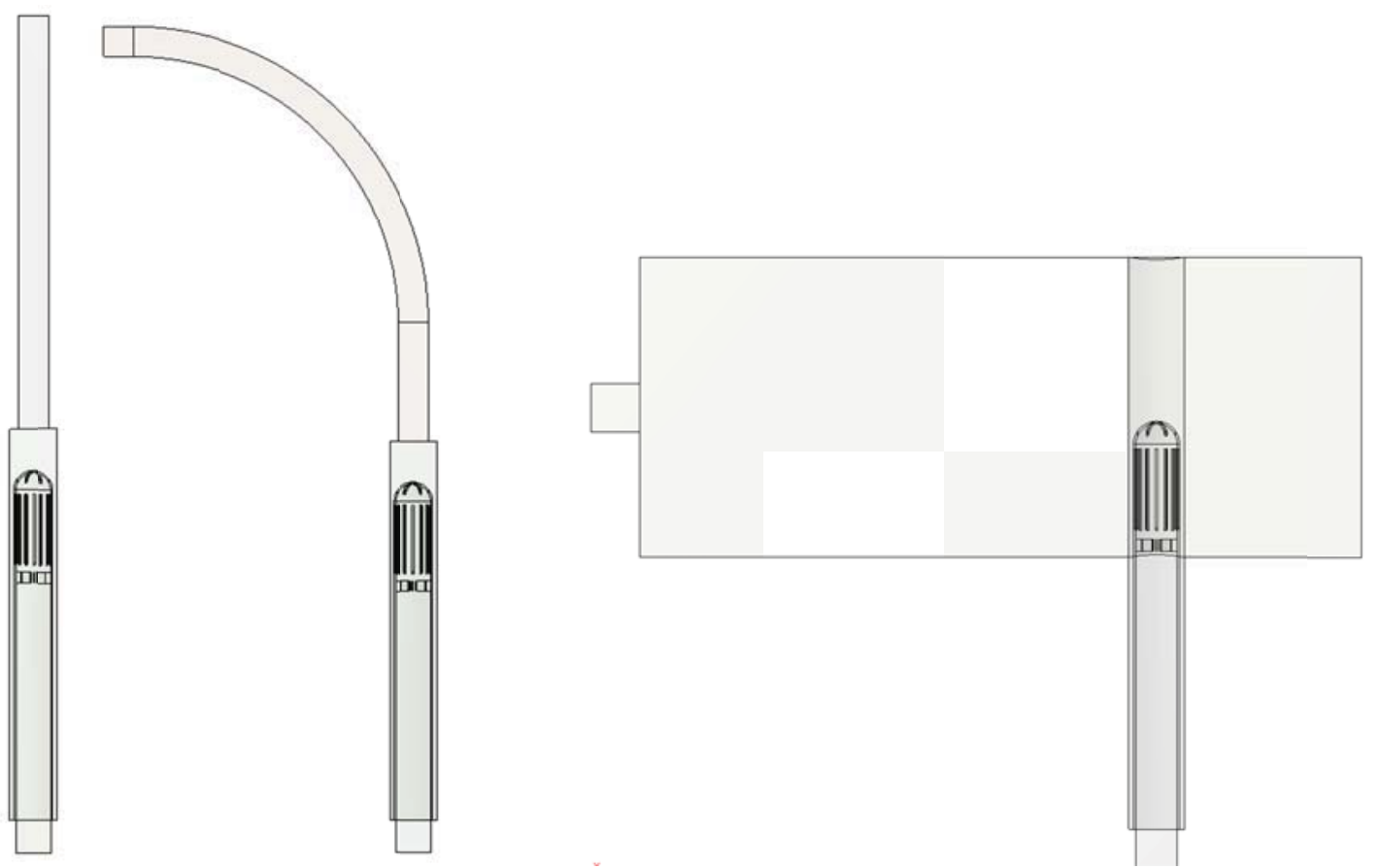

Figure 2: Nozzle mounting variation: straight pipe, bended pipe $90^{\circ}$, chamber

Measuring the pressure distribution (see Figure 3 ) the nozzle sprays on a moving plate. This plate is equipped with a hole of $1 \mathrm{~mm}$ in diameter and $10 \mathrm{MPa}$ pressure sensor. For a given nozzle configuration, the pressure is measured as position dependent while the ith the sensor is slowly moving under the spraying nozzle. plate $\mathrm{w}$

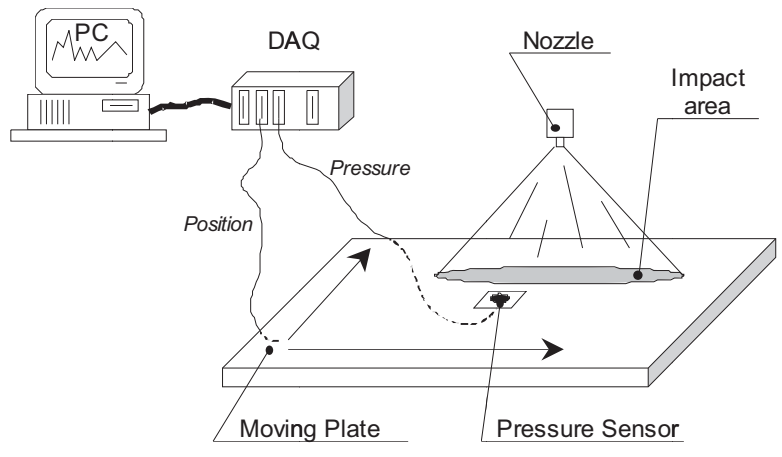

Figure 3: Experimental apparatus 


\section{EXPERIMENTAL RESULTS}

Both nozzles have a narrow footprint (see Figure 4 and Figure 5). The depth of the foot print is about $4 \mathrm{~mm}$. The length of the foot print for nozzle $A$ is approx. $60 \mathrm{~mm}$ and for nozzle $B 70 \mathrm{~mm}$. The footprint of nozzle A with stabilizer $C$ has a nice rectangular profile. Nozzle B with stabilizer D has a significant peek on one side and fall on the second side. It is probably caused by some inaccuracies in production.
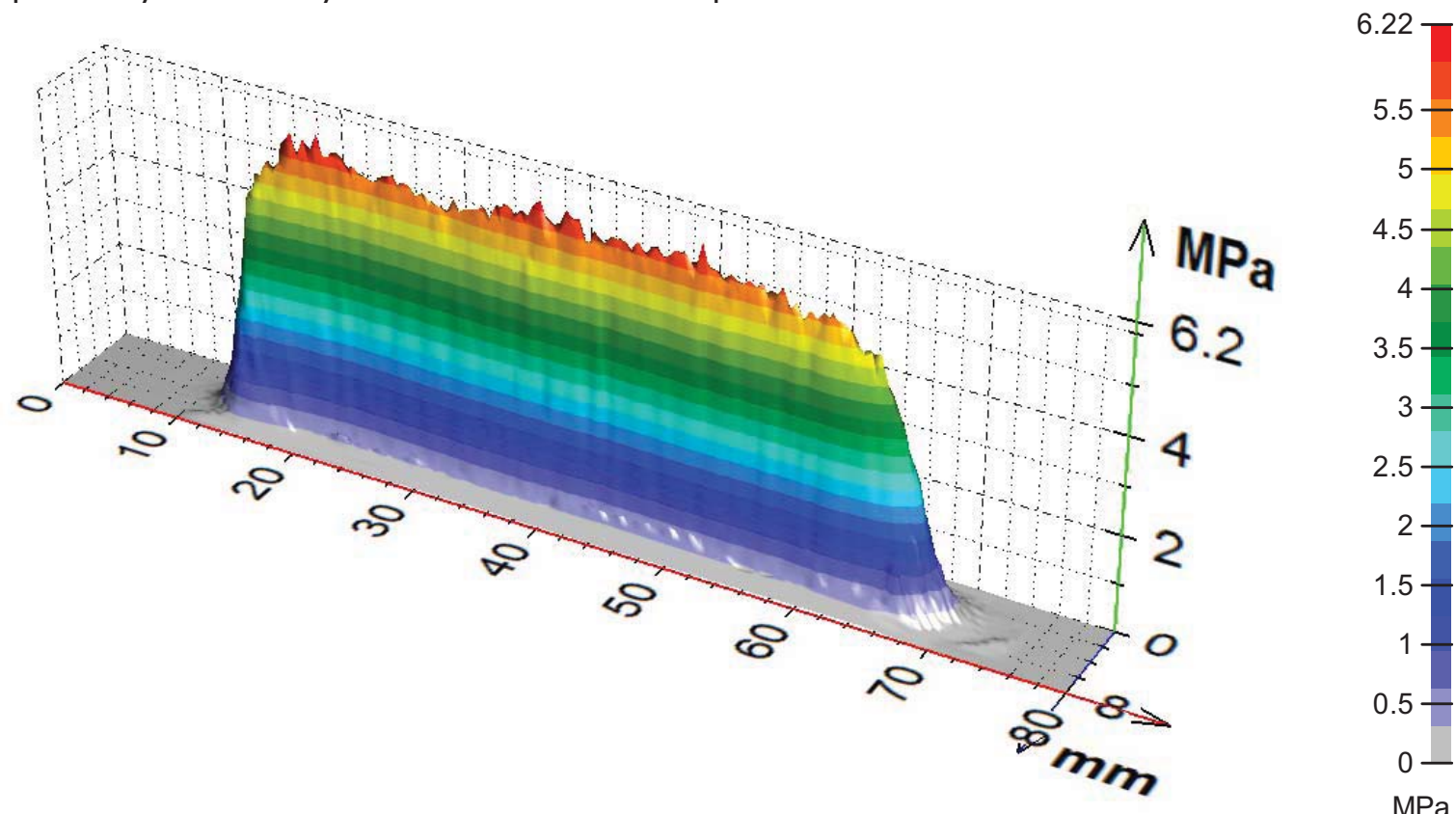

Figure 4: Measured pressure distribution for experiment E1 (nozzle A)

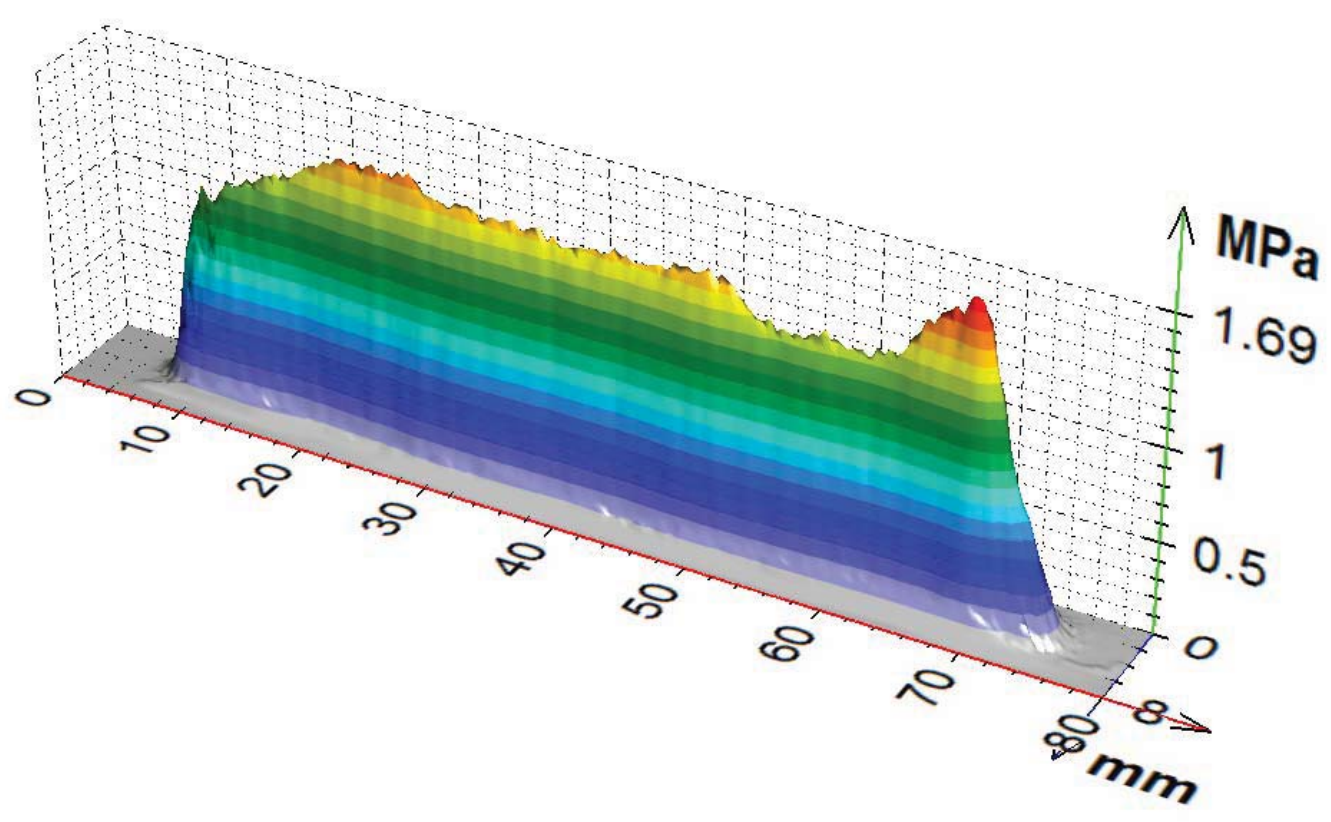

Figure 5: Measured pressure distribution for experiment E5 (nozzle B)

Figure 6 and Figure 7 show the average impact pressure in depth direction (averaging section 0 to $8 \mathrm{~mm}$ ). To better compare the measurements with an offset angle of $0^{\circ}$ with 
an offset angle of $180^{\circ}$ the data are flipped back in Figure 6 . It is obvious from the results that the measurements with the chamber give lower impact values. In both cases (chamber and pipe) a regulated water pressure of $25 \mathrm{MPa}$ was measured in the pipe $1 \mathrm{~m}$ from the exit of the pipe. The average impact decrease is $6.2 \%$. Comparing these two measurements with different offset angles in the chamber there is only a slight increase of the impact for experiment $\mathrm{E} 1$ in section from $58 \mathrm{~mm}$ to $65 \mathrm{~mm}$. The maximum difference of the impact in that area is $4.3 \%$. No significant change was observed when comparing the results with a straight and bended pipe.

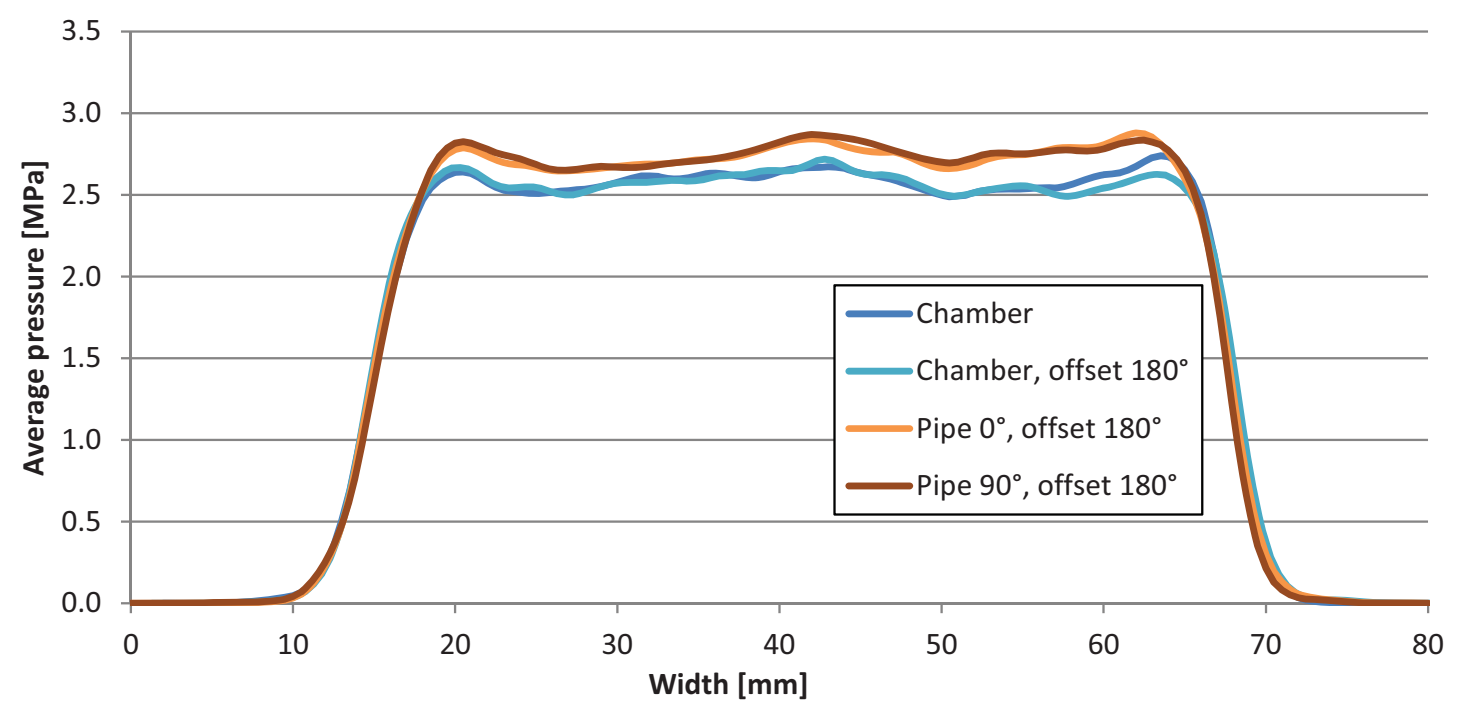

Figure 6: Nozzle A with stabilizer C

Nozzle B with stabilizer D was also tested with both pipes, straight and bended. The measurements showed that nozzle $B$ with newly designed stabilizer $D$ is more sensitive to different mounting than nozzle A with stabilizer D. Figure 7 showed that the influence is not symmetrical. The difference between attaching to the straight and bended pipe is $7.9 \%$ on the left side and only $4.3 \%$ on the right side. Repeatability of the measurement was tested with this nozzle. The maximum difference is $2.1 \%$ and the average difference is $0.6 \%$.

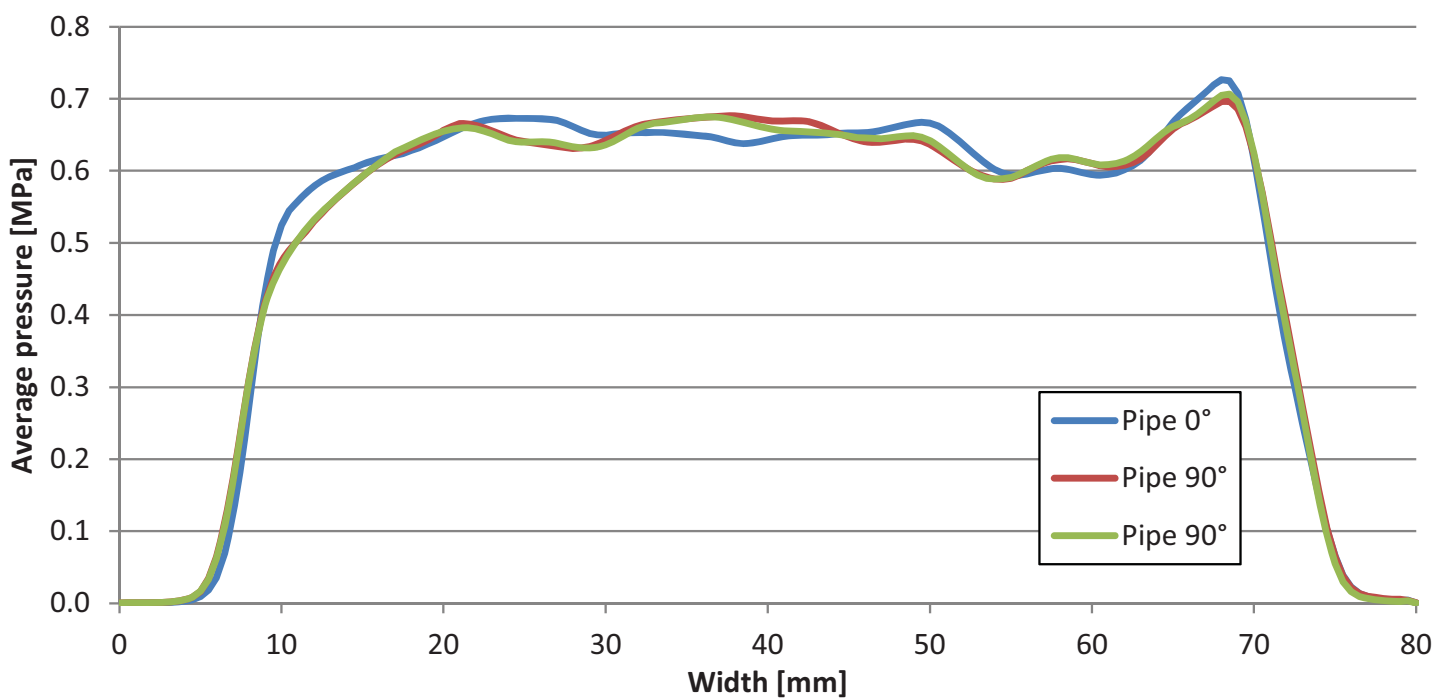

Figure 7: Nozzle B with stabilizer D 


\section{NUMERICAL SimULATION}

Numerical simulation in the ANSYS CFX 13.0 [5] was used to model fluid flow into the inlet piping and water stabilizer. Numerical simulation was prepared to better understand the fluid flow inside and to confirm the experimental results. The results of the numerical simulation can be used for a detailed analysis and the impact of different boundary conditions can be checked.

The models for numerical simulation were prepared based on the experiments (see Table 2). The CFD simulation was focused on the internal fluid flow which means that the outflow to open space and mixed water with air were not considered. The CFD models were prepared to study the influence of the inlet piping and the stabilizer on the impact pressure. The descaling nozzles used in the experiments were not considered in the numerical simulation. Two types of the fluid domain (two types of the stabilizers $C$ and $D$ see Figure 1) and three types of the inlet piping (pipe $0^{\circ}$, pipe $90^{\circ}$, and chamber see Figure 2) were modelled. The fluid domains consist of inlet (pipe), domain in stabilizer and outlet (short straight pipe), see Figure 8 . The fluid domains were considered to be symmetrical and were modelled as a half model. The boundary conditions in the CFD simulation were as follows: on the inlet, mass flow according to measurements during the experiments was used, on the outlet, a static pressure of zero was setup and the reference pressure corresponded with water pressure.

Table 2: List of CFD simulation

\begin{tabular}{|cccc|}
\hline Simulation & Stabilizer & Pressure [MPa] & Mounting \\
\hline 1 & C & 25 & pipe $0^{\circ}$ \\
2 & C & 25 & pipe $90^{\circ}$ \\
3 & C & 25 & chamber \\
\hline 4 & D & 25 & pipe $0^{\circ}$ \\
5 & D & 25 & pipe $90^{\circ}$ \\
6 & D & 25 & chamber \\
\hline
\end{tabular}
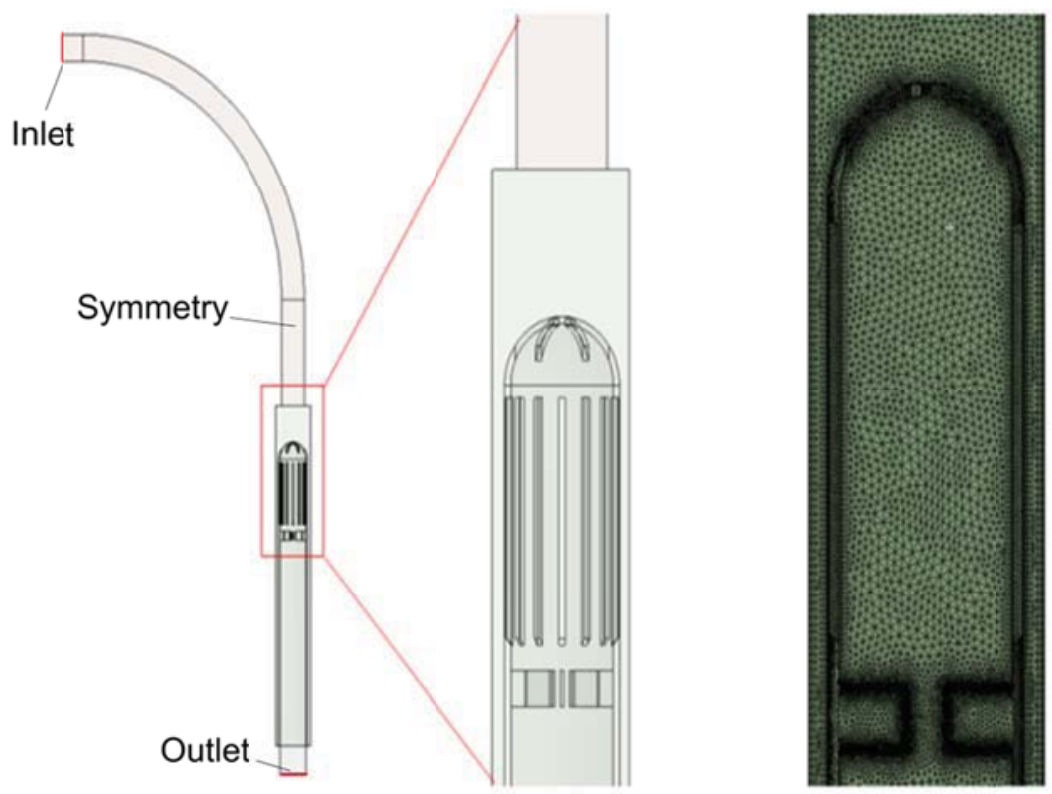

Figure 8: Fluid domain with mesh

01076-p.6 


\section{CFD RESULTS}

The results of the numerical simulation were evaluated for all considered variants (see Table 2.). The parameters which were monitored in the CFD simulations are presented in Table 3. The fluid flow into the domain was calculated for all the variants and presented by distribution of the velocity (see Figure 9 and Figure 10). The simulation of the fluid flow presented by velocity streamline gives a good idea about the impact of each configuration on the results. The values of pressure presented in Table 3 comply with total pressure and absolute pressure considered in the simulations which corresponds with the measured pressure (25 $\mathrm{MPa})$. To better assess each considered variant parameter loss coefficient was prepared and evaluated. The loss coefficient indicates the total pressure loss generated by each configuration. The loss coefficient is given by the following equation:

$$
\text { loss_coefficient }=\frac{\Delta p}{\frac{1}{2} \rho v^{2}}
$$

Table 3: Monitored parameters in the CFD simulations

\begin{tabular}{|cccccc|}
\hline \multicolumn{7}{c|}{ Stabilizer C } \\
\hline Mounting & $\begin{array}{c}\text { Total pressure inlet } \\
{[\mathrm{MPa}]}\end{array}$ & $\begin{array}{c}\text { Total pressure outlet } \\
{[\mathrm{MPa}]}\end{array}$ & $\begin{array}{c}\text { Velocity inlet } \\
{\left[\mathrm{m} \mathrm{s}^{\wedge}-1\right]}\end{array}$ & $\begin{array}{c}\text { Velocity outlet } \\
{\left[\mathrm{m} \mathrm{s}^{\wedge}-1\right]}\end{array}$ & $\begin{array}{c}\text { Loss coefficient } \\
{[-]}\end{array}$ \\
\hline pipe $0^{\circ}$ & 0.2357 & 0.0529 & 13.13 & 10.20 & 2.126 \\
pipe $90^{\circ}$ & 0.2428 & 0.0531 & 13.13 & 10.20 & 2.208 \\
chamber & 0.1395 & 0.0534 & 7.42 & 10.20 & 3.143 \\
\hline \multicolumn{7}{c}{ Stabilizer D } \\
\hline pipe $0^{\circ}$ & 0.1856 & 0.0533 & 13.13 & 10.20 & 1.539 \\
pipe $90^{\circ}$ & 0.2083 & 0.0533 & 13.13 & 10.20 & 1.804 \\
chamber & 0.1468 & 0.0542 & 7.42 & 10.21 & 3.379 \\
\hline
\end{tabular}

The velocity distribution presented in Figure 9 and Figure 10 shows the impact of the inlet piping. The velocity distribution for the configuration with a straight pipe and for both stabilizers is very uniform and the velocity distribution and fluid flow is symmetrical through the whole domain. The velocity distribution is quite variable in the configuration with the input bending pipe and it is affected by the angle of bending. In this case, the stabilizer cannot adequately accommodate and stabilize the fluid flow and therefore the velocity distribution on the entrance into the nozzle is deformed. The velocity distribution for the configuration with the chamber is relatively uniform, but the chamber has an impact on the initial velocity entering the nozzle. To study the impact of piping and stabilizer on the impact pressure the parameters on the outlet of the fluid domain were evaluated. One of these parameters was velocity and it is presented in Figure 11 and Figure 12 as output velocity distribution. The velocity in these figures was evaluated through the width of the output and corresponds with the velocity which enters into the nozzle. 


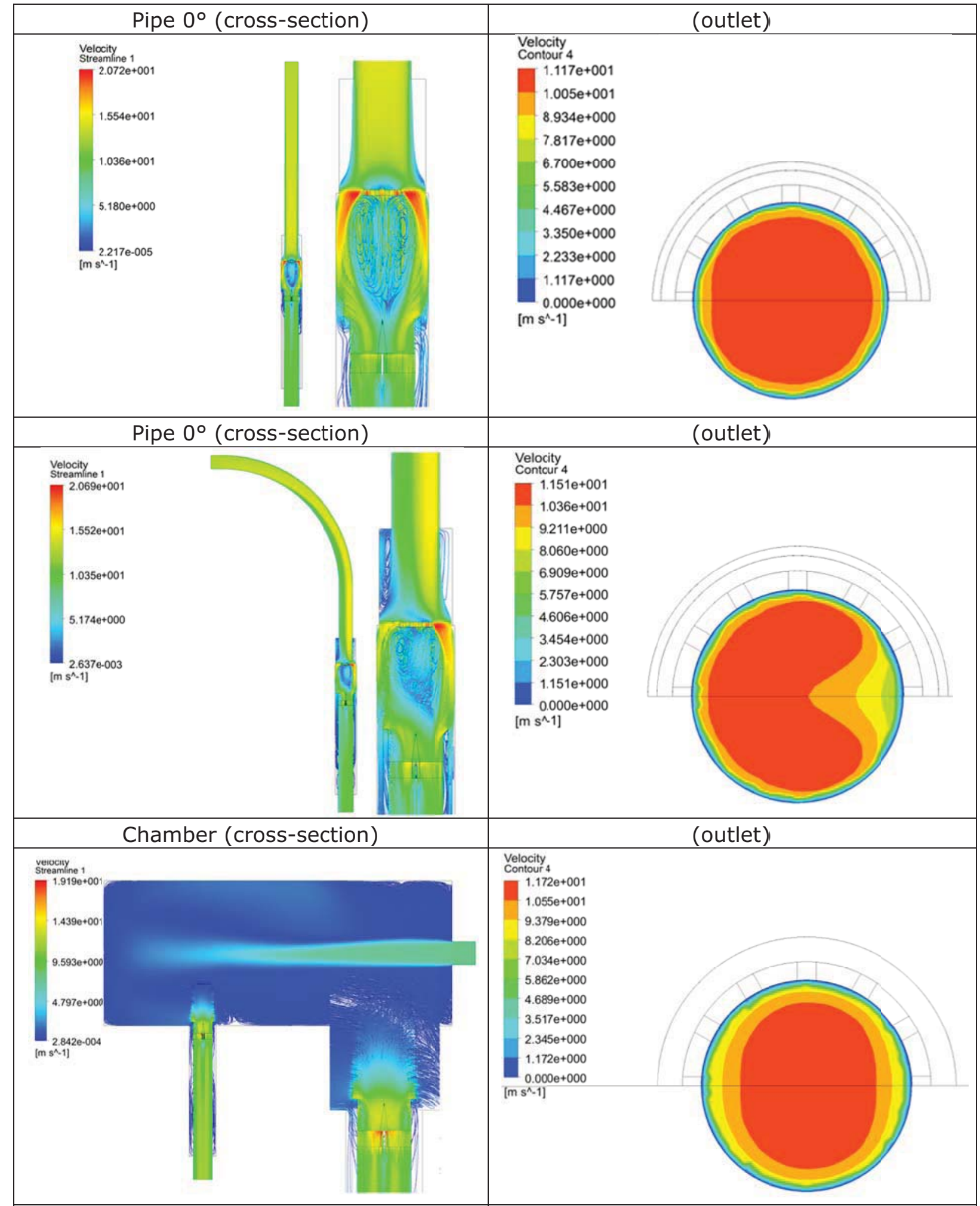

Figure 9: Velocity distribution of stabilizer C 


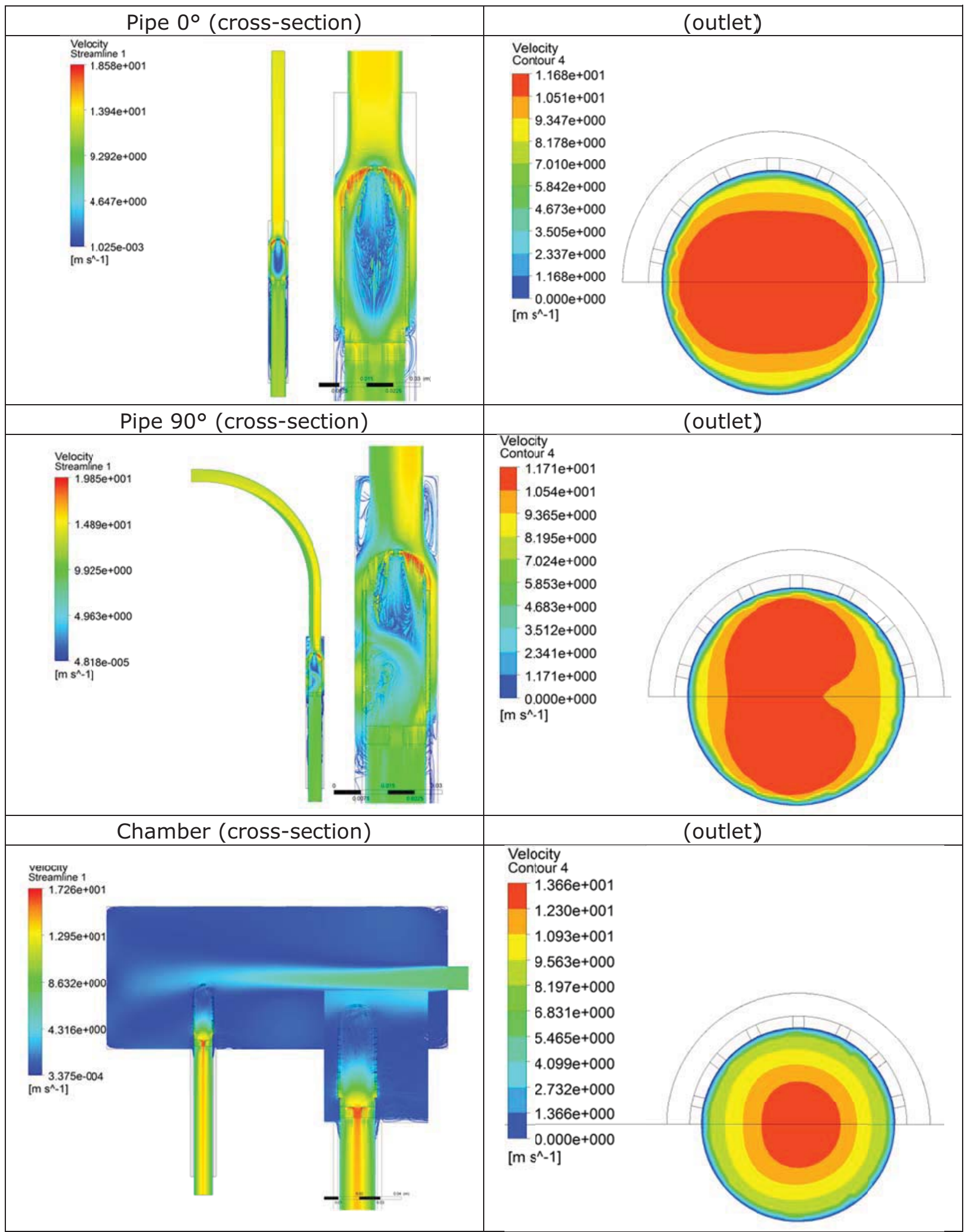

Figure 10: Veløcity distribution of stabilizer D 


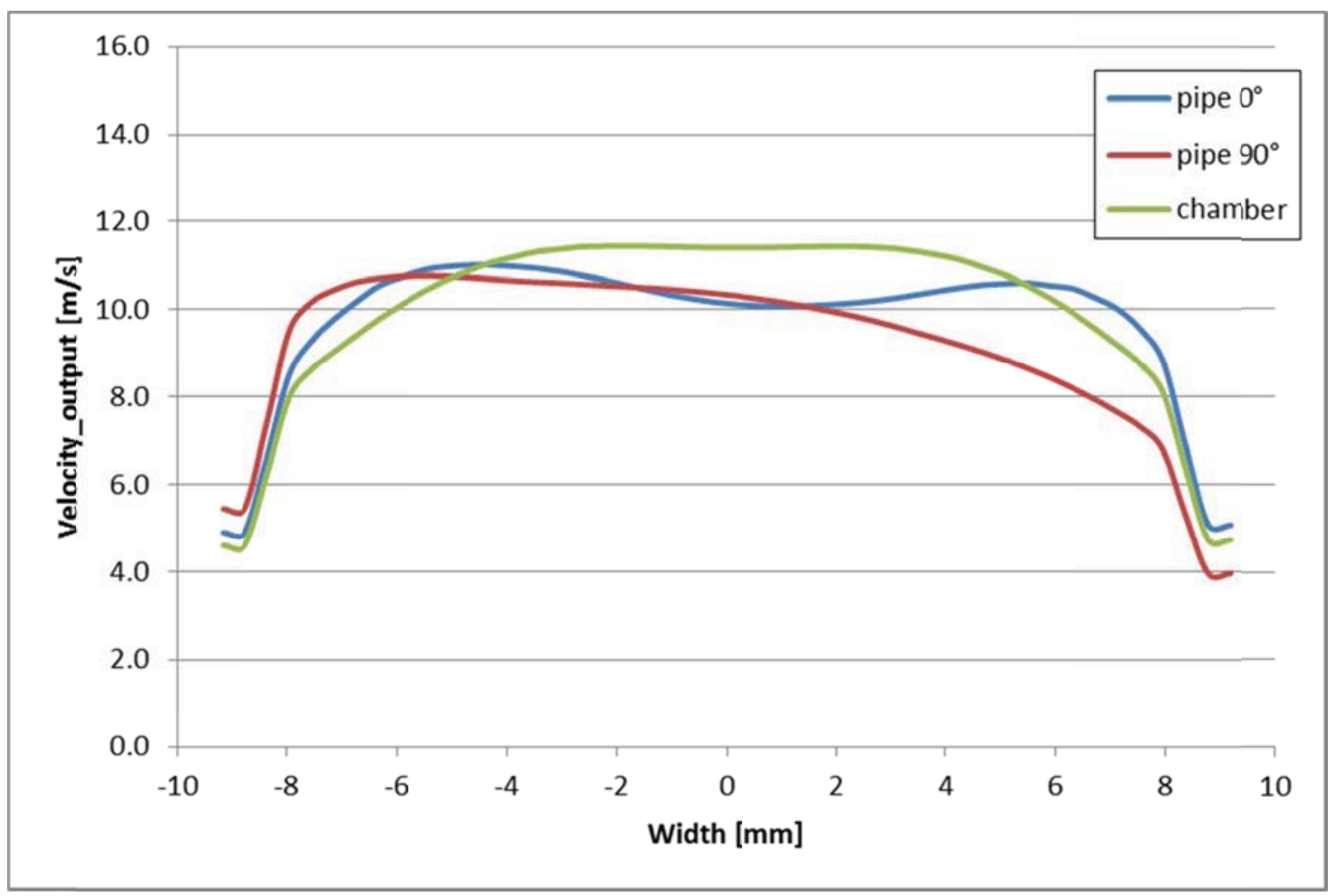

Figure 11: Output velocity distribution of configuration with stabilizer C

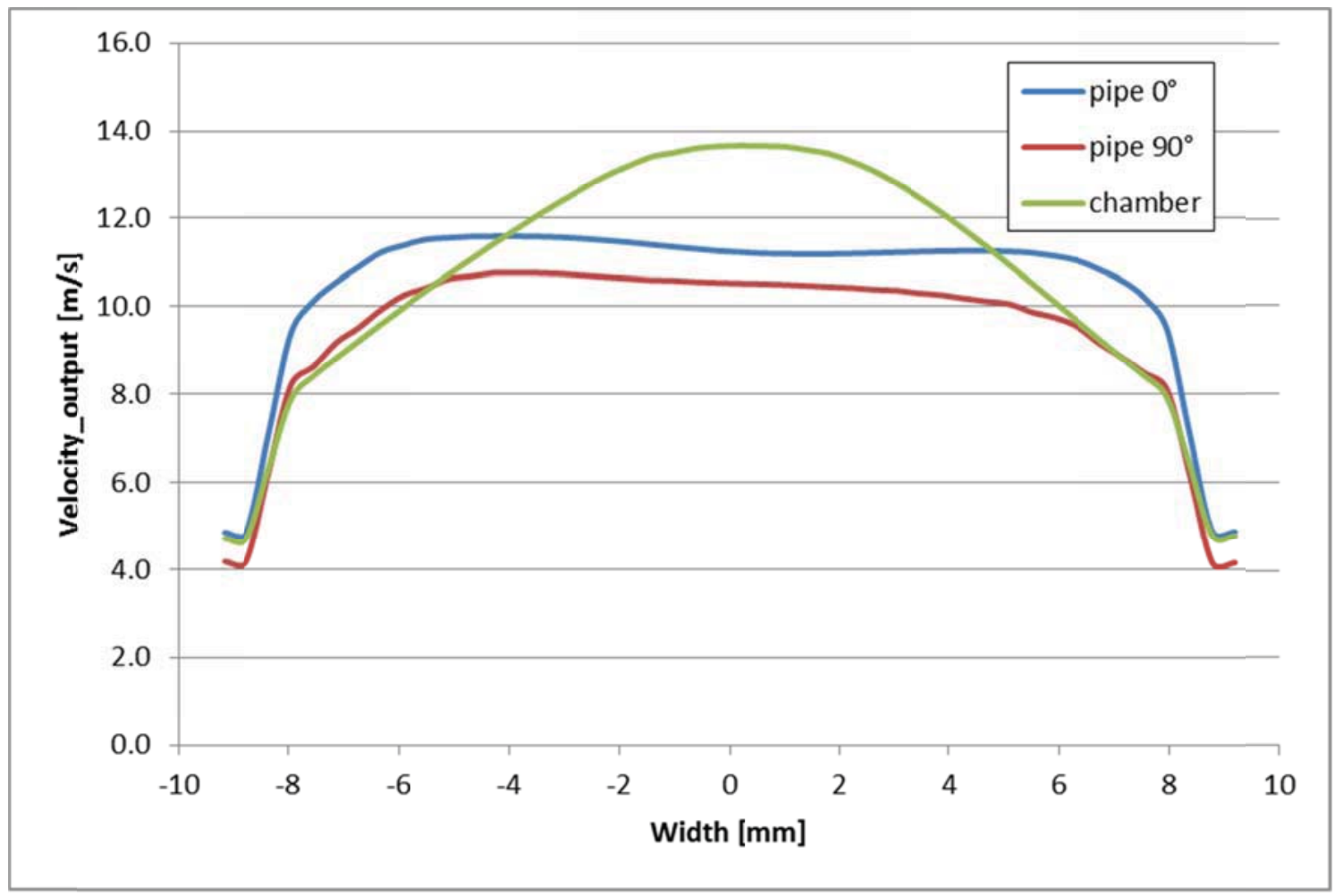

Figure 12: Output velocity distribution of configuration with stabilizer D 


\section{Conclusion}

Seven spray impact measurements were conducted with high pressure descaling nozzles. The measurements showed that the impact distribution does not depend only on nozzle type and the used water stabilizer but also how the nozzles are mounted and on the way the water is supplied. When the nozzle is mounted on to the big chamber the resulting impact is about $6.2 \%$ lower in comparison with measurements where the nozzle is mounted directly on to the pipe. It was also found that the stabilizer with a centre stick has a better stabilizing effect. Nevertheless, the differences in results were not very big and the maximum difference was $7.9 \%$.

Several configurations with two types of stabilizers and three types of input piping were prepared and calculated. For simulation of the fluid flow in all fluid domains CFD analyses were used. The analyses consist of the fluid flow through the inlet piping and water stabilizers. From CFD analyses the parameters characterizing the fluid flow were evaluated. One of these parameters is velocity. The distribution of the velocity was presented for all considered configurations. The results obtained from CFD analyses confirmed the results explored in the measurements. The second significant parameter which was evaluated, the loss coefficient, confirmed that the water stabilizer D produces a lower pressure loss then water stabilizer $\mathrm{C}$. The values of the loss coefficient presented in Table 3 are lower for stabilizer D, but water stabilizer $C$ has loss coefficient values very uniform. More uniform values of loss coefficient for water stabilizer $C$ indicate lower sensitivity on the input piping than the sensitivity for stabilizer D. The CFD analyses demonstrate the impact of input pipe and stabilizer on the final value of the impact pressure. These results confirm the assumption that a proper design of the inlet piping and suitable stabilizer can affect the value of impact pressure. During the optimization process of high pressure hydraulic descaling it is necessary to consider basic parameters such as spray length, nozzle distance and so on, as well as mounting.

\section{ACKNOWLEDGEMENT}

The paper presented has been supported by the internal grant of the Brno University of Technology focused on specific research and development No. FSI-S-11-20 - Heat Transfer Intensification.

\section{RefERENCES}

[1] Blazevic D. T.: Hot strip mill operations, Volume V, Scale, Sun Lakes, Arizona, USA, December 2005

[2] Frick J. W.: More efficient hydraulic descaling header designs, MPT International 2/2004, http://www.lechler.de/pdf/descaling header designs.pdf

[3] Kotrbáček P., Horský J., Raudenský M., Pohanka M.: Influence of parameters of hydraulic descaling on temperature losses and surface quality of rolled material, Metal forming 2004, pp. 367-370. ISBN 3-937057-08-0

[4] Pohanka M.: Two-dimensional correction of data measured using a large pressure sensor. In Computational methods and experimental measurements XI. Halkidiki: WIT Press, 2003, pp. 587-596. ISBN 1-85312-969-0

[5] ANSYS 13.0 CFX help, ANSYS, Inc. http://www.ansys.com/ 